\title{
Ambiguity as Grasp: The Reworking of Sense
}

\section{Karl E. Weick}

Stephen M. Ross School of Business University of Michigan, Ann Arbor, MI 48109-1234. E-mail: karlw@umich.edu

\begin{abstract}
Ambiguity may lead us to insert abstractions into our experience that create a greater number of unanticipated, unintended consequences. When people move closer to the flux of ambiguity, they work to make sense of it. High reliability organizations react to ambiguity by increasing it momentarily. To increase ambiguity is to grasp more of the situation, to refrain from simplifications, and to strive for a workable level of ambiguity. This argument is developed through a focus on connotations of ambiguity, assumptions for organizing around ambiguity, and implications for practice. To grasp ambiguity is to adopt an attitude of wisdom.
\end{abstract}

To trace something unknown back to something known is alleviating, soothing, gratifying and gives moreover a feeling of power. Danger, disquiet, anxiety attend the unknown - the first instinct is to eliminate these distressing states. First principle: any explanation is better than none. ... The first idea which explains that the unknown is in fact the known does so much good that one "holds it for true" (Nietzsche, 1968, p. 51; cited in Lagadec, 2010, p. 3).

We mistake the change of a feeling of doubt into a feeling of assurance as knowledge (Bacon, 2012, p. 54).

\section{Introduction}

T here are at least two answers to the question, 'how do organizations react to ambiguity'. First, faced with ambiguous information, organizations tend to reach for assurance in what they already know. Second, they may act within ambiguity and deepen it momentarily, accepting that it is malleable, chronic, disrupting and unsettling. The second possibility is the topic of this article. The second possibility is an implied subtext in ongoing work on high reliability organizing.
High reliability organizations react to ambiguity by increasing it momentarily. This occurs when they pay more attention to discrepancies, complications, details and ignorance, all in an effort to sustain ongoing projects. To increase ambiguity is to grasp more of the situation. Ambiguity is not about solving puzzles where all the pieces lie on the table awaiting rearrangement. Instead, to 'grasp' ambiguity is to comprehend it adequately, to simplify it self-consciously and to accept that the simplification is fleeting, incomplete and will fail. To grasp ambiguity is to refrain from the simplifications inherent in types, categories, stereotypes and habits. Instead, one settles for a workable level of ambiguity, but no more. To grasp ambiguity is to impose a plausible next step, but then to treat plausibility as both transient and as something compounded of knowledge and ignorance. Grasp is the acceptance that behind ambiguity lies more ambiguity, not clarity. It is the realization that clarity is costly because it discards so much potential information. And it is the realization that progress produces complication rather than resolution. In Rachel Halliburton's (2002) words, 'Clarification should not be confused with simplification'.

To develop this argument, I first review several connotations of the word 'ambiguity' so that we have a 
better grasp of what the 'it' is to which organizations are responding and what the 'who' is that is doing the responding. Second, I propose four assumptions about organizing that influence our understanding of how dynamic organizations react to ambiguity. Third, I conclude with implications for acting with ambiguity to ambiguity.

\section{Connotations of the word 'ambiguity'}

Traditionally, the word 'ambiguity' means that events are open to more than one interpretation (American Heritage Dictionary, 1992, p. 56), a meaning that is suited for organizations since they are sites for multiple meanings of contested issues. These contested issues are based on plausible but different interpretations, doubts and uncertainties. Mary Douglas (2002, p. 47) begins to refine our thinking when she contrasts 'ambiguity' with 'anomaly' and describes ambiguity as 'a statement capable of two interpretations' and an anomaly as 'an element that does not fit a set or series'. Ambiguity connotes reliability that can be threatened in one of two ways, either by multiple plots that are imposed on an unfolding sequence or by an error of omission or commission that disrupts a sequence.

Example:The stuck semaphore

On October 22, 1979, 5 people were killed and 51 were injured in Invergowrie Scotland when a passenger train traveling at $60 \mathrm{mph}$ slammed into a stopped passenger train in front of it. The semaphore signal that was supposed to signal the speeding train to stop 'was raised above the horizontal by at least 6 degrees but by not more than 10 degrees: in such a position it should have been taken to be an imperfectly exhibited signal and thus treated as at Danger, but for some reason the train driver passed the signal and continued into the occupied section' (Report on the Collision that occurred on 22nd October 1979 at Invergowrie in the Scottish region British Railways, Her Majesty's Stationery Office, January 16, 1981, p. 10). It was concluded that since the signal was at an angle between proceed and stop, and closer to proceed, the driver interpreted it as proceed and drove into the rear of the stopped train just around a bend.

'Uncertainty' is perhaps the most common synonym for ambiguity. But uncertainty differs because it also tends to imply something more general and less forceful. Uncertainty 'denotes a lack of assurance or conviction' (American Heritage Dictionary, 1992, p. 1872). Information that is 'uncertain' 'may range from a mere falling short [of certainty] to an almost complete lack of knowledge or conviction especially about the result or outcome of something' (Merriam-Webster, 1984, p. 841).

\section{Example: Escape fire}

At Mann Gulch, foreman Wagner Dodge tried to save his crew from a fire blow-up that was coming right at them, by burning grass off the ground in front of them. This would burn a hole in the fire where his crew could lie down. That way the fire would burn around them, not over them. Only Dodge understood what he was doing. The rest of the crew didn't. Their interpretation was that Dodge had gone crazy since he was lighting a fire right in the middle of their escape route. The combination of high wind, fire behind and in front of them, slippery steep terrain, tools that had been dropped farther down the hill, and a person yelling 'to hell with that, I'm getting out of here' conveys confused desperation and neither assurance nor conviction.

People who study sensemaking often refer to ambiguous events as 'equivocal', by which they mean an event is of uncertain significance and open to two or more interpretations. For example, some ancients argued that the sun revolved around the earth (geocentric) while others claimed the earth revolved around the sun (heliocentric). The elements were the same, but the interpretations were different. A straightforward example of an equivocal event is one that is interpreted as both similar to and different from previous experience and therefore of uncertain significance.

Example: 'Considerable' avalanche danger in backcountry skiing

The loss of three lives in a backcountry avalanche at Tunnel Creek, on the backside of Cowboy Mountain, 75 miles east of Seattle, was preceded by an avalanche warning that was the most equivocal of the 5 degrees of warning possible. The warning level of 3, labeled 'considerable,' means 'Natural avalanches possible. Human triggered avalanches probable. Be increasingly cautious in steeper terrain' (Tremper, 2008, pp. 304-5). As one member of the skiing party put it, "I was uneasy about the "considerable" danger of an avalanche but didn't speak up' (Michelson, 2012). True, the specific warning urged 'caution,' but the 16 people in the backcountry ski party were all experienced skiers and the warning was of 'uncertain significance'. It was both a warning and a challenge. What was rendered dangerously insignificant by this equivocal warning were additional red flags such as new snow, a proposed trail that was actually a gully that consolidated snow movements, a group 
composed of 16 people which is 12 more than the recommended size of 4 , a general forecast of avalanche danger, the proposed skiing area marked as 'off limits,' and confident locals who were eager to demonstrate their prowess on this slope.

A different meaning of the word ambiguity is captured by the word 'crucible'. A crucible is a severe test, 'a place, time, or situation characterized by a confluence of powerful intellectual, social, economic or political forces' (American Heritage Dictionary, 1992, p. 448). A compact use of the word is Taylor and Van Every's statement that organization is realized 'in the crucible of the quotidian' (2000, preface, p. $x$ ), which, for the rest of us, means organization is realized in the daily tests (conversations) at work, tests that come at us from all directions, with multiple meanings and with incessant demands for prioritization. As Robert Chia (2005) puts it, 'Managing is firstly and fundamentally the task of becoming aware, attending to, sorting out, and prioritizing an inherently messy, fluxing, chaotic world of competing demands that are placed on a manager's attention' (p. 1092).

\section{Example: Confusion in a railyard}

A northbound train, the Silver Star, was stopped at the station at Hamlet, North Carolina. The last car on the train was business car number 310 , where the executives were eating breakfast. The radio in the business car had been switched to the yard radio channel while the train was being serviced. A brakeman in the nearby railyard, not knowing that the transmission button on his radio was stuck in the 'On' position, yelled, 'Hell! Stop the movement, hold on a second dammit. I'm all screwed up'. Grabbing the radio handset on board the business car, the startled vice president of Seaboard Coast Line Railroad identified himself and demanded the offending party immediately reciprocate, to which came the reply,'I may be all screwed up, but I ain't that screwed up!' (Riddell, 1999, p. 81).

In the context of organization and organizing, ambiguity is sometimes treated as the relaxation of order. The image is from Chia (1999, p. 225). 'Organization.... [is a] reality-maintaining activity which stabilizes the "real" sufficiently for us to act purposefully in response to a deluge of competing and attention-seeking external stimuli. ... (M)erely relaxing the deeply entrenched organizational and institutional habits, which keep "organizations" together and which enable them to be thought of as "thing-like", is itself sufficient to allow change to occur of its own volition'. This 'change' is often experienced as ambiguity. The relaxation of reality-maintaining activity is evident in the following tragedy.

\section{Example: Friendly Fire}

After the Gulf War, on April 14, 1994, twenty six people were killed by friendly fire when two friendly helicopters were shot down by two US Air Force F-15 fighters during peace-keeping operations. The F-15 pilots mistook the two US helicopters for Russian Hinds helicopters. A crew of 19 Air Force officers in an AWACs aircraft that was monitoring and controlling all 4 aircraft, did nothing to stop the shoot down. 'The Hind was constructed in his [lead F-15 pilot] mind's eye at the intersection of a sufficiently ambiguous stimulus, a strong set of expectations, and a perverse desire to see an enemy target' (Snook, 2000, p. 76).

It is also possible to view ambiguity as a stage in the process of how understanding develops across time. William Schutz (1979) proposed that understanding passes through three stages: superficial simplicity, confused complexity, profound simplicity. In the beginning, our ideas have a flavour of superficial simplicity. We all have our favourite High Reliability Organization slogans (e.g., keep it simple stupid), swift diagnoses (e.g., there is too much theory), standard remedies (e.g., we need another rule), and automatic simplifications (e.g., it is operator error). Gradually, we become aware of exceptions to the simplifications and our understanding becomes more complex and confused. This is progress because we are trying to grasp a broader range of inputs than was true before. Having worked within confusion and having used it as a pretext to rework ideas, we then may find profound simplifications that are now more meaningful than they were originally. For example, out of confusion may come simplicities such as 'nothing is permanent', 'hubris lowers reliability', 'complication improves simplification' or 'capability controls awareness'.

Example: Novice brakeman develops understanding.

Bob, an old-hand as a railroad brakeman, was training a new man on the job and instructed the novice to 'Do everything I do'. The train they were working had passed by a siding and was 'backing into the siding so that an oncoming train loaded with servicemen could pass. Bob lined the switch and was swinging his lantern to give the circular back-up sign [to the engineer] when the handle snapped off and the globe flew into the woods. The cubbing brakie did just as Bob told him, making the circular motion twice and letting his own lantern fly. Hurriedly grabbing a fusee, Bob then frantically taught him the hand signal to get the engineer to stop the oncoming train' (Riddell, 1999, p. 79). 


\section{Assumptions}

Assumptions make a difference in how one organizes to deal with ambiguity. To 'grasp' ambiguity is to organize, mindful of at least four constraints. Organizing itself is

1. Always ambiguous.

2. Always a substitution.

3. Always interrupted.

4. Always relational.

\subsection{Always ambiguous}

William James (1987, p. 782) described the 'original' ambiguity, captured by sense and feeling, that is temporarily obscured by layers of imposed concepts, strategies and tactics. 'Pure experience in this state is but another name for feeling or sensation. But the flux of it no sooner comes than it tends to fill itself with emphases, and these salient parts become identified and fixed and abstracted; so that experience now flows as if shot through with adjectives and nouns and prepositions and conjunctions'. Substituting emphases and abstractions, as we will see below, creates a greater number of unanticipated, unintended consequences. This is why people have to be aware and mindful of what any concept excludes and of the words used to abstract portions of the flow.

It is easy to conclude that this move from flux to 'active condensation' (Irwin, 1977, p. 26) is rare and has little to do with ambiguity. However, the transformation is more common and less stable than we think. Moments of accomplishment also tend to be moments of complication. As John Dewey's puts it, each achievement settles something. But, 'from the side of what comes after, it complicates, introducing new problems and unsettling factors. There is something pitifully juvenile in the idea that "evolution," progress, means a definite amount of accomplishment which will forever stay done' (Dewey, 1922, p. 285).

We have no choice but to work within ambiguity, so how we rework that ambiguity is what matters.

\subsection{Always a substitution}

William James (1987, p. 1008) is famous for this sentence 'If my reader can succeed in abstracting from all conceptual interpretation and lapse back into his immediate sensible life at this very moment, he will find it to be what someone has called a big, blooming buzzing, confusion, as free from contradiction in its "much-atonceness" as it is all alive and evidently there'. This is the constant ambiguity mentioned in assumption 1 . What is less well known is that a few sentences later he makes the more crucial point that 'The intellectual life of man consists in his substitution of a conceptual order for the perceptual order in which his experience originally comes'
(James, 1987, pp. 1008-9, italics in original). We do not realize how much we ignore, but we realize it when projects are interrupted and structures break down. What we then see are failed substitutions that previously concealed ambiguity that was always there.

\subsection{Always interrupted}

Expectations and project are the locales and names for most of the reality-maintaining work of organizing. This suggests that better management is 'mindful when it is aware of its own expectations, the limited horizon of these expectations, and the need for ongoing corrections' (Czarniawska, 2005, p. 271). Awareness of expectations often increases both when projects are disrupted and when components of the disruption become the object of attention. 'In every waking moment, the complete balance of the organism and its environment is constantly interfered with and as constantly restored.... Life is interruptions and recoveries. ... At these moments of a shifting of activity, conscious feeling and thought arise and are accentuated' (Dewey, 1922, pp. 178-179, italics added).

An interruption does not generate a cool abstraction. Instead, it generates a 'charged thought'. As Sid Winter argues, organizational action is not choice points and cost benefit analysis. Instead, deliberation occurs in response to 'the stimulus provided by the experienced frustration and perceived inadequacy of existing habitual responses' (Winter, 2013, p. 129). When emotions are engaged by a task, but established habits are insufficient to accomplish it, interruption becomes a generative trigger for learning (see Barton \& Sutcliffe, 2009). In effect, habits are turned inside out. And the participant reworks the past, present and future into a more adaptive next step.

What is important for our understanding of ambiguity are indications that ambiguity takes the form of habits turned inside out which reveals their histories and their futures. That more complex picture generates a new framework to deal with the interruption. And whatever framework does temporarily structure the interruption, still remains a substitution that glosses over 'blooming, buzzing confusion'.

\subsection{Always relational}

An organization is not the individual writ large, but the individual is a group writ small. 'Each individual carries those parts of the collective knowledge that makes possible individual action with regard to organizational concerns' (Cook \& Yanow, 1993, p. 385).

One way to think about the individual as a 'group writ small' is to propose that organization emerges in communication. Taylor and Van Every (2000) argue that conversation is the site for organizational emergence 
and language is the textual surface from which organization is read. Thus, organizations are talked into existence locally, and are read from the language produced there, which can generate clarity as well as ambiguity. The intertwining of text and conversation turns flux into a situation that is comprehensible and that can then serve as a springboard for action.

If we pull back from individual conversations and adopt a more macro view, the organization remains conversational. Taylor et al. (2000) portray such an organization as a network of multiple, overlapping, loosely connected conversations, spread across time and distance [that] collectively preserves patterns of understanding that are more complicated than any one node can reproduce. The distributed organization literally does not know what it knows until specific actors articulate it. This ongoing articulation gives voice to the collectivity and enables interconnected conversations and conversationalists to see what they have said, to understand what it might mean, to learn who they might be and potentially to say things differently with different effects.

For an organization to act, 'its knowledge must undergo two transformations: (1) it has to be textualized [think conceptual substitution] so that it becomes a unique representation of the otherwise multiply distributed understandings [think ambiguity]; (2) it has to be voiced by someone who speaks on behalf of the network [think individual with "organizational concerns"] and its knowledge' (Taylor et al., 2000, p. 243). Communication, language, talk, conversation and interaction are crucial sites in organizing around ambiguity. Familiar phrases in talk related to crises, phrases such as 'Drop your tools' at Mann Gulch wildland fire, 'We are at takeoff' in the Tenerife Air disaster, 'If I don't know about it, it isn't happening' uttered by paediatricians before child abuse was discovered, 'This virus looks like St. Louis Encephalitis' when West Nile virus was misdiagnosed, 'Our pediatric heart cases are unusually complex' when Bristol Royal Infirmary's death rate was highest in UK, 'These fingerprints are a close enough match to the prints at the Madrid commuter train bombing' from FBI laboratory, 'That odor is bug spray' when odor was actually lethal gas escaping at Bhopal, all of these represent textual surfaces constructed at conversational sites where people made sense of prior actions in ways that constrained and normalized subsequent actions.

\section{The practice of managing ambiguity}

To move towards practice in the face of ambiguity, we first get our bearings from Todd LaPorte. 'We must act when we cannot foresee consequences; we must plan when we cannot know; we must organize when we cannot control' (La Porte, 1975, p. 345). With these imperatives in mind, the earlier arguments suggest the following as a framework for grasping ambiguity:

1. Every experience counts.

2. Every experience can be deepened.

3. Every experience is sifted conceptually.

4. Every experience 'makes' sense.

5. Every experience is composed of wary improvisation.

\subsection{Every experience counts}

Every experience modifies the experiencer, which means every experience counts. John Dewey makes this abundantly clear in his notion of the continuity of experience. 'The basic characteristic of habit is that every experience enacted and undergone modifies the one who acts and undergoes, while this modification affects, whether we wish it or not, the quality of subsequent experience. For it is a somewhat different person who enters into them ... (T)he principle of continuity of experience means that every experience both takes up something from those which have gone before and modifies in some way the quality of those which come after' (Dewey, 1997, p. 35). The person you are when you wade into ambiguity is modified by that experience. Therefore, when you encounter what looks like the same event in the future, it is not the same because you are not the same.

\subsection{Every experience can be deepened}

If you accept the assumption of continuity of experience, then there is a clear imperative for action: so act as to increase the meaning of present experience. 'Progress means increase of present meaning, which involves. ... complication and extension of the significance found within experience.... If we wished to transmute this generalization into a categorical imperative we should say: "So act as to increase the meaning of present experience.... (S)tudy the needs and alternative possibilities lying within a unique and localized situation" (Dewey, 2002, p. 283).

\subsection{Every experience is sifted conceptually}

To gain a clearer picture of what is implied and what is left out when one strives to grasp ambiguity, visualize your efforts as similar to working with a sieve, a utensil with a mesh filter that catches substances that have some set pattern but allows all other patterns to fall through and pile up below. The ideas that we use to keep from being overwhelmed by ambiguity constitute the mesh. 'A conceptual scheme is a sieve' (James, 1981, p. 455). 'The result of the thoughts' operating on the data given to sense is to transform the order in which 
experience comes into an entirely different order that of the conceived world... . The conceptual scheme is a sort of sieve in which we try to gather up the world's contents. Most facts and relations fall through its meshes, being either too subtle or too insignificant to be fixed in any conception. But whenever a physical reality is caught and identified as the same with something already conceived, it remains on the sieve, and all the predicates and relations of the conception with which it is identified becomes its predicates and relations too; it is subjected to the sieve's network, in other words'.

A good example of sifting is NASA's reaction to foam-shedding 82 seconds into the disastrous flight of the Columbia space shuttle. They labelled the shedding 'almost in-family', which meant that the shedding was treated as 'a reportable problem that was previously experienced, analyzed, and understood' (CAIB, 2003, p. 122).

That labelling was convenient, it could be fitted to pre-existing predicates and relations. But the labeling was wrong. The puff of smoke was treated as a familiar nuisance that could be fixed back on the ground. It is as if the puff was caught on the mesh of a sieve, linked to prevailing predicates and relations, and the more complete contextual data were treated as insignificant and too subtle for further attention.

To organize more mindfully in the face of ambiguity is to do the equivalent of changing the mesh of the sieve, re-examining facts and relations that fall through, and doubting that they are as subtle or insignificant as first thought. As we have argued, abstractions are abridgements of concrete flux. As we pay more attention to the seemingly subtle and insignificant, we experience more ambiguity. What is striking in all of this is that we are actually moving closer to the flux that was there before we imposed our framework on it, before it was 'sifted'. The experience of ambiguity, thus, provides a clearer look at the confluence that is responsible for an interruption.'Seeing is forgetting the names of the things one sees' (Weschler, 2008) and the forgetting is nothing less than the conversion of 'things' back into indeterminate situations that could be re-conceptualized more pragmatically with different labels. To forget the names of the things seen is to remove some but not all predicates.

\subsection{Every experience 'makes' sense}

When people move closer to the flux of ambiguity, they work to make sense of it by using the resources of (1) Social context, (2) Identity, (3) Retrospect, (4) salient Cues, (5) Ongoing projects, (6) Plausibility and (7) Enactment (Weick, 1995). These seven can be retained by means of the acronym, SIR COPE. These seven are important not only because they affect one's initial sense of what the ambiguous story may be, but more importantly, the seven influence the extent to which people will update and develop their sense of an ambiguous situation. These properties, in other words, have an effect on the willingness of people to rework their initial story and adopt a newer story that is more sensitive to the particulars of the present context. This reworking is far from an exercise in fantasy or elimination. Instead, one's sense of what is going on is constrained by agreements with others, consistency with one's own stake in events, the recent past, visible cues, projects that are demonstrably underway, scenarios that are familiar, and actions that have tangible effects. When one or more of these sources of grounding are themselves hazy, ambiguity deepens, moments are turned inside out and effort is directed towards assurance or rework. Other things being equal, given a choice among organizational designs, all of which seem to manage other issues equally well, the choice should favour a form that allows for more conversations, clearer identities, more use of elapsed action as a guide, unobstructed access to a wider range of cues, more focused attention on interruptions whenever projects are disrupted, wider dissemination of stories and deeper acceptance of the reality that people face situations that are of their own making.

\subsection{Every experience is composed of wary improvisation}

Interruptions and improvisation seem to go together, and this affinity suggests one possibility of how organizations react to ambiguity. Gilbert Ryle (1979) describes the improvisational quality of everyday life. '(T)o be thinking what he is here and now up against, he must both be trying to adjust himself to just this present once-only situation and in doing this to be applying lessons already learned. There must be in his response a union of some Ad Hockery with some know-how' (p. 129).

This is not making something out of nothing. Instead, it is 'on-the-spot surfacing, criticizing, restructuring and testing of intuitive understandings of experienced phenomena' while the ongoing action can still make a difference (Schon, 1987, Pp. 26-7). Familiar materials juxtaposed in an ambiguous assemblage are recombined in ways that are plausible given the context but unlikely to resolve the ensuing ambiguities. To improvise is to steer the existing ambiguity into further complications. To grasp ambiguity is to treat those further complications as normal, natural trouble.

\section{Conclusion}

Reliable organizing assumes that ambiguity is permanent, and interpretations are impermanent. Trouble occurs when we assume the opposite, namely, ambiguity 
is impermanent and interpretations are permanent. To grasp ambiguity is to rework sense, repeatedly, since both you and the world change continuously even though you continue to navigate using unchanging, discontinuous concepts. Organizing for high reliability is attuned to chronic ambiguity because it is sensitive to small failures, inaccurate simplifications, distractions, overlearned habits and pretensions to expertise (Weick \& Sutcliffe, 2007). The application of HRO principles can create a workable level of ambiguity, but not its complete disappearance. As more attention is directed to failing, simplification, operations, options and expertise, ambiguity lingers but its content shifts. It shifts towards things that people are better able to control, things such as earlier signs of failing, simplifications that ignore the significant and subtle, forecasts and memories that distort a clear picture of what is happening right now, potential resources for adaptation that are at hand even though unused, and doubts in search of people with answers.

In a more general sense, to grasp ambiguity is to adopt an attitude of wisdom. 'The essence of wisdom ... lies not in what is known but rather in the manner in which that knowledge is held and in how that knowledge is put to use. To be wise is not to know particular facts but to know without excessive confidence or excessive cautiousness. ... [T] o both accumulate knowledge while remaining suspicious of it, and recognizing that much remains unknown, is to be wise' (Meacham, 1990, pp. 185, 187). To hold this attitude is to remain somewhat wary, doubtful and dubious, which means there is always some ambiguity woven into action. Viewed in this context, an increase in ambiguity, relative to what you already are experiencing, is not that disabling nor does it lead you to flee into the first interpretation that promises assurance.

\section{Acknowledgement}

I am grateful to KyleWeick for his help in reworking this manuscript.

\section{References}

American Heritage Dictionary. (1992), American Heritage Dictionary of the English Language, (3rd edn), Houghton Mifflin, New York.
Bacon, M. (2012), Pragmatism: An Introduction, Polity, Malden.

Barton, M. and Sutcliffe, K. (2009), 'Overcoming Dysfunctional Momentum: Organizational Safety as a Social Achievement', Human Relations, Volume 62, Number 9, pp. 1327-1356.

CAIB (2003), Columbia Accident Investigation Board: Report, Vol. 1, US Government, Washington.

Chia, R. (1999), 'A 'Rhizomic' Model of Organizational Change and Transformation: Perspectives from a Metaphysics of Change', British Journal of Management, Volume 10, pp. 209-227.

Chia, R. (2005), 'The Aim of Management Education: Reflections on Mintzberg's 'Managers not MBAs', Organization Studies, Volume 26, Number 7, Pp. 1090-1092.

Cook, S.D.N. and Yanow, D. (1993), 'Culture and Organizational Learning', Journal of Management Inquiry, Volume 2, Number 4, pp. 373-390.

Czarniawska, B. (2005), 'Karl Weick: Concepts, Style, and Reflection', Sociological Review, Volume 53, pp. 267-278.

Dewey, J. (1922-2002), Human Nature and Conduct, Dover, Mineola.

Dewey, J. (1997), Experience and Education, Free Press, New York.

Douglas, M. (2002), Purity and Danger, Routledge, London.

Halliburton, R. (2002), Panto Makeover for the Bard. London Evening Standard.

Irwin, R. (1977), Notes Toward a Model, Exhibition Catalog for the Robert Irwin Exhibition, Whitney Museum of American Art, April 16-May 29, 1977, Pp. 23-31 (New York: Whitney Museum of American Art)

James, W. (1981), The Principles of Psychology, Vol. 1, Cambridge University Press, Harvard.

James, W. (1987), Writings: 1902-1910. New York, Library of America.

La Porte, T.R. (1975), 'Complexity and Uncertainty: Challenge to Action', in La Porte, T.R. (ed.), Organized Social Complexity, Princeton University, Princeton, NJ, pp. 332-356.

Lagadec, P. (2010), 'Beyond Charted Research: A Personal Tribute to Todd R. LaPorte', Journal of Contingencies and Crisis Management, Volume 19, Number 1, pp. 3-8.

Meacham, J.A. (1990), 'The Loss of Wisdom', in Sternberg, R.J. (ed.), Wisdom, Cambridge, New York, NY, pp. 181-211.

Merriam Webster. (1984), Merriam Webster's Dictionary of Synonyms: A Dictionary of Discriminated Synonyms with Antonyms and Analogous and Contrasted Words, Merriam Webster, New York.

Michelson, M. (2012), 'Tunnel Vision', Outside Magazine, 14 November.

Nietzsche, F. (1968), Twilight of the Gods, Penguin, Baltimore.

Riddell, D. (1999), From the Cab: STORIES from a Locomotive Engineer Pentrex, Pasadena, CA.

Ryle, G. (1979), 'Improvisation', in Ryle, G. (ed.), On Thinking, Blackwell, London, pp. 121-130.

Schon, D.A. (1987), Educating the Reflective Practitioner, Jossey-Bass, San Francisco.

Schutz, W. (1979), Profound Simplicity, Bantam, New York.

Snook, S. (2000), Friendly Fire, Princeton University, Princeton.

Taylor, J.R. and Van Every, E.J. (2000), The Emergent Organization: Communication as its Site and Surface, Erlbaum, Mahwah.

Tremper, B. (2008), Staying Alive in Avalanche Terrain, Mountaineers Books, Seattle.

Weick, K.E. (1995), Sensemaking in Organizations, Sage, Thousand Oaks.

Weick, K.E. and Sutcliffe, K.M. (2007), Managing the Unexpected: Resilient Performance in an Age of Uncertainty, Jossey-Bass, San Francisco.

Weschler, L. (2008), Seeing Is Forgetting the Name of the Thing One Sees: A Life of Contemporary Artist Robert Irwin, University of California, Berkeley.

Winter, S.G. (2013), 'Habit, Deliberation, and Action: Strengthening the Microfoundations of Routines and Capabilities', The Academy of Management Perspectives, Volume 27, Number 2, pp. 120-137. 